\title{
IMPLEMENTASI ANALYTIC HIERARCHY PROCESS PADA PERANCANGAN SISTEM PENDUKUNG KEPUTUSAN REKRUTMEN KARYAWAN DI PT. $X$ BERBASIS VISUAL STUDIO 2019
}

\author{
Riko Dwi P. ${ }^{1}$, Arie Restu Wardhani ${ }^{2 *}$, Chauliah Fatma Putri ${ }^{3}$ \\ 1,2,3 Program Studi Teknik Industri, Fakultas Teknik, Universitas Widyagama Malang \\ *Email Korespondensi : arierestu@widyagama.ac.id
}

\begin{abstract}
ABSTRAK
Masalah perekrutan karyawan adalah permasalahan umum yang terjadi di suatu perusahaan tidak terkecuali di PT. X. Proses yang cukup panjang karena masing data yang tersimpan masih belum terkomputerisasi menyebabkan staff HRD sering melakukan kesalahan pendataan calon karyawan karena dokumen hilang maupun tertukar. Hal ini mengakibatkan pihak pengambil keputusan untuk perekrutan karyawan merasa kesulitan dalam pengambilan keputusan karena kriteria yang digunakan belum dapat teruji konsisten dan validasi berdasarkan data dan bobot nilai dari masing-masing peserta. Selain itu, jika pelamar cukup banyak, pengambil keputusan akan merasa kesulitan dalam menentukan calon karyawan terbaik sesuai dengan lowongan jabatan yang dibutuhkan. Penelitian ini bertujuan untuk merancang sistem pendukung keputusan dengan implementasi metode AHP (Analytic Hierarchy Process) untuk perekrutan karyawan sehingga dapat diperoleh calon karyawan dengan bobot tertinggi. Perancangan sistem pendukung keputusan ini menggunakan software visual studio 2019. Hasil dari penelitian ini adalah sistem perekrutan menjadi lebih akurat karena dapat mengurangi tingkat kesalahan staff HRD pada proses awal pendataan dokumen sampai dengan proses pendataan hasil psikotes dan wawancara. Sistem ini juga dapat membantu pengambil keputusan dalam menentukan calon karyawan berdasarkan bobot tetinggi.
\end{abstract}

Kata kunci : Sistem pendukung keputusan, Analytic Hierarcy Process, Visual studio 2019

\begin{abstract}
The problem of the employees' recruitment is a general issue that occurs in a company, including in PT. X. The process is too long because each data stored is still not computerised. That can cause the HRD staff errors in inputting the data collection of the prospective employees because of lost or exchanged documents. The process of deciding the recruitments is difficult and complicated because the criteria cannot be verified and validated based on data and weight values from each participant. Also, the decision-makers perceive the difficulties due to the enormous candidates with the different capabilities which should be matched vacancy needed. This study aims to design a decision support system with the implementation of the AHP (Analytic Hierarchy Process) method for employee recruitment so that candidates with the highest weight can be decided. The design of this decision support system utilises 2019 visual studio software. The result yields the more accurate of the recruitment support system because it can reduce the human error of HRD staff in the initial process of document data collection through the data collection process of psychological test results and interviews. This system can also assist decision-makers in determining prospective employees who have higher weights.
\end{abstract}

Keywords: Decision support system, Analytic Hierarchy Process, Visual studio 2019

\section{PENDAHULUAN}

Dalam dunia bisnis, perkembangan teknologi informasi cukup menunjang dalam peningkatan produksi bahkan peningkatan kualitas sumber daya manusia yang ada. Sumber daya manusia yang berkualitas dan profesional merupakan faktor utama dalam membantu organisasi mencapai tujuan. Salah satu kegiatan dalam pemilihan sumber daya manusia 
yang berkualitas adalah dengan rekrutmen karyawan yang merupakan suatu tahap strategis untuk mengidentifikasi calon karyawan yang tepat. Sebuah organisasi bisnis sudah pasti membutuhkan tenaga kerja yang memiliki kualitas dan kemampuan yang sesuai dengan kualifikasi dan kebutuhan organisasi bisnis tersebut (Handoyo, 2013; Mardianto, 2014; Maulana, 2017).

Sementara itu, PT. X masih belum memanfaatkan sistem perekrutan calon karyawan yang terkomputerisasi. Penerapan sistem perekrutan manual pada PT. X menyebabkan yang panjang dan rumit, seperti : perekapan data pelamar, pemilihan data yang sesuai kualifikasi, penilaian dari pengalaman kerja, pemilihan sesuai usia maksimal, pendidikan terakhir, proses pemanggilan pelamar, penilaian psikotest dan tes wawancara. Setiap tahap yang dilakukan membutuhkan waktu yang cukup lama terutama dari segi mengakumulasi dan menyimpulkan calon karyawan yang kompeten. Selain itu, kesalahan dalam pemberkasan dari staff HRD, mengakibatkan dokumen hilang atau tertukar mengakibatkan adanya pendataan ulang di akhir sesi recruitment.

Berdasarkan uraian permasalahan diatas, maka diperlukan suatu sistem perekrutan karyawan yang terkomputerisasi untuk menghindari kesalahan saat pemberkasan dokumen dan saat pemilihan calon karyawan dapat lebih cepat dan sistematis. Kemudian, pemilihan karyawan juga dapat dibantu dengan metode Analisis keputusan seperti metode AHP (Analytic Hierarcy Process). Hal ini dapat mendukung tim seleksi dalam mengambil keputusan.

\section{Perekrutan Karyawan}

Perekrutan karyawan merupakan suatu proses seleksi calon karyawan kapabilitasnya sesuai dengan kualifikasi yang dibutuhkan organisasi/perusahaan (Mardianto, 2014). Proses ini sangat memperhatikan kriterian perekrutan seperti motivasi kerja, kemampuan calon karyawan, keahlian, dan pengetahuan sesuai spesifikasi yang diperlukan perusahaan (Meiastoko, 2013). Adapun kriteria perekrutan dapat diuraikan sebagai berikut.

a) Keahlian Dasar.

Keahlian dasar dapat dikelompokkan menjadi tiga yaitu (1) technical skill yaitu keahlian teknis yang harus dimiliki oleh karyawan pelaksana; (2) human skill merupakan keahlian individual untuk memecahkan masalah dan pengambilan keputusan teknis. Biasanya kemampuan ini dimiliki oleh pimpinan menengah; (3) conceptual skill merupakan kemampuan konseptual untuk perencanaan dan Analisa yang bersifat strategis bagi perusahaan. Biasanya kemampuan ini dimiliki oleh pucuk pimpinan.

b) Pengalaman.

Perusahaan akan lebih cenderung untuk mencari calon tenaga kerja yang sudah berpengalaman dibanding calon tenaga kerja yang baru lulus sekolah

c) Umur

Umur merupakan poin penting yang mendapat perhatian khusus dalam proses seleksi. Hal ini karena umur mempengaruhi kondisi fisik dan mental tenaga kerja, kemampuan dan tanggung jawab.

d) Jenis Kelamin

Jenis Kelamin menjadi pertimbangan khusus dalam proses seleksi terutama untuk sifat pekerjaan tertentu, waktu kerja, dan peraturan pemerintah.

e) Pendidikan

Pendidikan merupakan jenjang untuk meningkatkan kemampuan dan pengetahuan bagi seseorang. Pendidikan meliputi pendidikan formal dan informal. Faktor ini harus dimiliki pelamar yang nantinya akan menentukan hasil seleksi.

Analytical Hierarchy Process (AHP)

Analytical Hierarchy Process (AHP) dikembangkan oleh Thomas L. Saaty pada tahun 1970-an. Metode ini merupakan salah satu model pengambilan keputusan 
muhltikriteria yang dapat membantu kerangka berpikir manusia dimana faktor logika, pengalaman pengetahuan, emosi dan rasa dioptimasikan ke dalam suatu proses sistematis.

Selain itu, AHP merupakan salah satu metode untuk membantu menyusun suatu prioritas dari berbagai pilihan dengan menggunakan berbagai kriteria. Karena sifatnya yang multikriteria, AHP cukup banyak digunakan dalam penyusunan prioritas (Handoyo, 2013). Langkah-langkah yang dilakukan dalam metode AHP sebagai berikut:

1. Mendefinisikan masalah dan menentukan solusi yang diinginkan.

2. Membuat struktur hierarki yang diawalai dengan tujuan utama. Secara umum, struktur hierarki dapat dilihat pada Gambar 1.

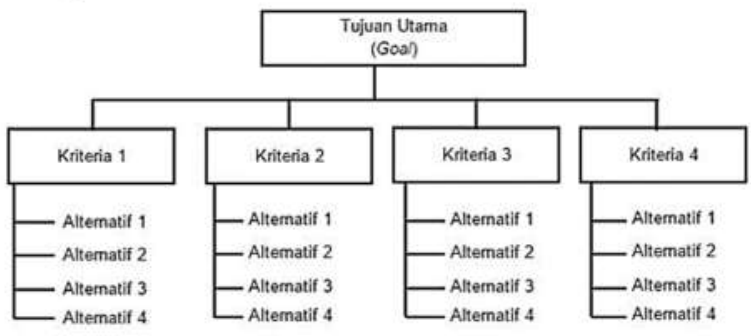

Gambar 1. Struktur Hierarki AHP

3. Pembobotan AHP

Untuk setiap kriteria dan alternatif, kita harus melakukan perbandingan berpasangan (pairwaise comparison) yaitu membandingkan setiap elemen dengan elemen lainnya pada setiap tingkat hirarki secara berpasangan sehingga didapat nilai tingkat kepentingan elemen dalam bentuk pendapat kualitatif. Adapun bobot kriteria dapat berdasarkan perbandingan berpasangan dievaluasi dalam skala kepentingan (Saaty's scale) 1 - 9 pada Tabel 1 .

Tabel 1. Skala Tingkat Kepentingan

\begin{tabular}{|l|l|}
\hline Tingkat Kepentingan & \multicolumn{1}{|c|}{ Definisi } \\
\hline 1 & Sama pentingnya dibanding yang lain \\
\hline 3 & Moderat pentingnya dibanding yang lain \\
\hline 5 & Kuat pentingnya dibandingyang lain \\
\hline 7 & Sangat kuat pentingnya dibanding yang lain \\
\hline 9 & Ekstrim/mutlak pentingnya dibanding yang lain \\
\hline $2,4,6,8$ & $\begin{array}{l}\text { Nilai diantara dua penilaian yang berdekatan } \\
\text { Jika elemen i memiliki salah satu angka diatas ketika } \\
\text { dibandingkan dengan it maka memiliki nnilai } \\
\text { kebalikannya ketika dibandingkan dengan elemen i. }\end{array}$ \\
\hline Reciprocal & \\
\hline
\end{tabular}

Hasil rasio evaluasi dari skala AHP disajikan dalam bentunk matrik. Ordo-ordo matrik dinormalisasi dan secara diagonal ditambah untuk mendapatkan nilai eigen.

4. Konsistensi Rasio

Menurut Makassau (2012), Skala kepentingan AHP juga memberikan pertimbangan terhadap pertanyaan mengenai logika konsistensi dari evaluator. Indeks konsistensi (CI) adalah perhitungan matematis untuk setiap perbandingan berpasangan matrik perbandingan. CI ini menyatakan deviasi konsistensi. Kemudian indeks acak (Random index/RI), sebagai hasil dari respon acak yang mutlak dibagi dengan CI dihasilkan rasio konsistensi (CRs). Semakin tinggi CRs maka semakin rendah konsistensi, demikian juga sebaliknya. Rumus perhitungan Konsistensi Index (CI):

$\mathrm{CI} \quad=$ Indeks Konsistensi

$$
C I=\frac{\lambda_{M a k s}-n}{n-1}
$$

$\lambda_{\text {Maks }}=$ nilai eigen terbesar dari maktriks berordo $\mathrm{n}$.

$n \quad=$ jumlah kriteria 
AHP mengukur seluruh konsistensi penilaian dengan menggunakan Consistency Ratio (CR), yang dirumuskan :

$$
C R=\frac{C I}{R I}
$$

Dimana nilai Random Index (RI) berdasarkan perhitungan Saaty, dapat dilihat dari Tabel 2.

Tabel 2. Nilai Random Index (RI)

\begin{tabular}{|c|c|c|c|c|c|c|c|c|c|c|}
\hline $\mathrm{N}$ & 1 & 2 & 3 & 4 & 5 & 6 & 7 & 8 & 9 & 10 \\
\hline $\mathrm{RI}$ & 0,00 & 0,00 & 0,58 & 0,90 & 1,12 & 1,24 & 1,32 & 1,41 & 1,45 & 1,49 \\
\hline
\end{tabular}

Suatu matriks perbandingan adalah konsisten bila nilai CR tidak lebih dari sama dengan $0,1(10 \%)$. Jika tidak, maka penilaian yang telah dibuat mungkin dilakukan secara random dan perlu direvisi.

\section{METODE}

Diagram alir yang digunakan dalam perancangan sistem pendukung keputusan pada penelitian ini adalah seperti pada Gambar 2.

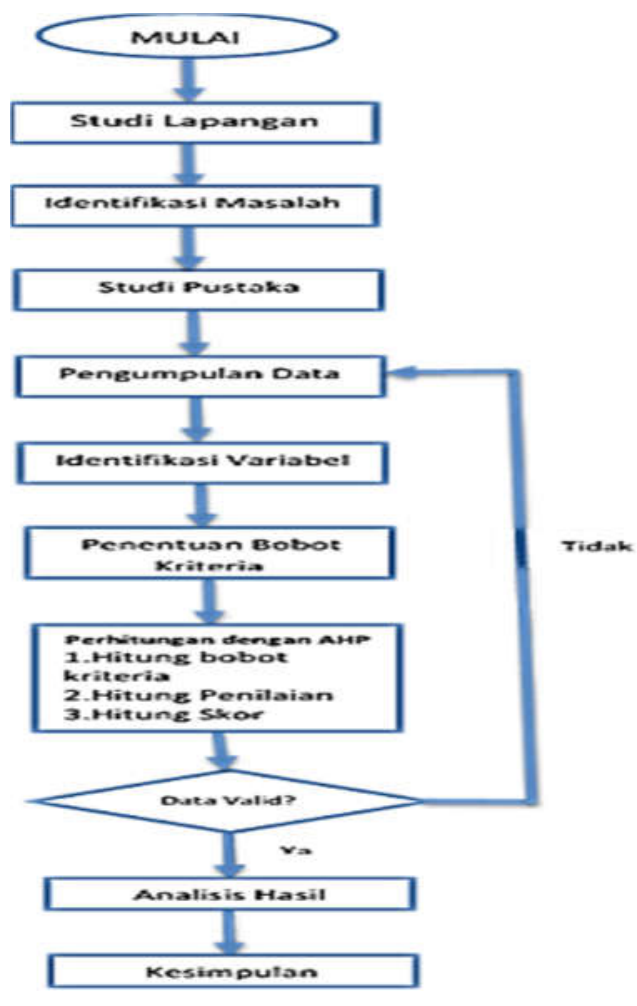

Gambar 2. Diagram Alir Penelitian

\section{Tahap 1. Studi Pendahuluan}

Tahapan awal dimulai dari melakukan pengumpulan data, observasi lapangan dan pengamatan, serta melakukan interview kepada bagian HRD mengenai sistem perekrutan karyawan pada PT. X.

\section{Tahap 2. Identifikasi Masalah}

Peneliti memformulasi masalah berdasarkan pengamatan dan interview pada staff HRD. Dalam hal ini perumusan masalah yang dapat disusun adalah bagaimana merancang 
sistem pendukung keputusan untuk rekrutmen karyawan dengan mengimplementasikan sistem AHP (Analytic Hierarchy Process).

\section{Tahap 3. Studi Pustaka}

Peneliti melakukan studi pustaka yang terdiri artikel ilmiah, skripsi dan buku-buku yang terkait dengantopik penelitian. Studi pustaka ini bertujuan untuk memperoleh gambaran mengenai studi yang dilakukan oleh peneliti-peneliti terdahulu. Sehingga, penelitian ini dapat memberikan rekomendasi bagi perusahaan mengenai sistem pendukung keputusan yang lebih sistematis dan mengurangi human error.

\section{Tahap 4. Pengumpulan Data}

Pada tahap ini pengumpulan data dilakukan dengan pengumpulan data primer dan data sekunder. Data primer adalah sumber data yang langsung memberikan data kepada pengumpul data. Sedangkan data sekunder adalah sumber data yang tidak langsung memberikan data kepada pengumpul data, misalnya lewat orang lain atau lewat dokumen.

Data primer diperoleh dari hasil wawancara dengan HRD PT. X dan observasi di lapangan. Untuk data sekunder, penelitian ini membutuhkan data calon karyawan periode Agustus 2019 yang mengirimkan berkas lamaran pekerjaan ke PT. X.

Jenis penelitian ini menggunakan data kuantitatif dan deskriptif. Peneliti menggunakan data kuantitatif karena data yang diperoleh berupa variabel yang dapat dihitung dan diperoleh melalui peroses wawancara langsung. Selain itu, data deskriptif yang diperoleh dari analisis keadaan atau kondisi pada PT.PG Rajawali I yang selanjutnya digunakan untuk menganalisis dan menentukan variabel deskriptif yang dibutuhkan dalam penelitian ini.

\section{Tahap 5. Identifikasi Variabel}

Variabel atau objek pada penelitian ini terdiri atas: data pengalaman kerja, data usia, data pendidikan, data psikotest dan data wawancara. Variabel - variabel tersebut yang digunakan untuk merancang sistem pada penelitian ini.

\section{Tahap 6. Penentuan bobot Kriteria}

Penelitian ini memanfaatkan 5 (lima) kriteria, berdasarkan interview yang dilakukan dengan staff HRD PT. X. Adapun lima kriteria tersebut adalah:

a) Pengalaman kerja

Pengalaman kerja merupakan hal yang penting dipertimbangkan sebagai salah satu kriteria perusahaan dalam proses rekrutmen. Semakin lama calon karyawan pernah bekerja, maka semakin kompeten ia dalam bekerja. Hal ini juga dapat dijadikan acuan bahwa calon karyawan tersebut mampu beradaptasi dengan perubahan lingkungan kerja.

b) Usia

Usia harus mendapat perhatian karena akan mempengaruhi kondisi fisik, mental, kemampuan kerja, dan tanggung jawab seseorang. Karyawan muda umumnya mempunyai fisik yang lebih kuat, dinamis dan kreatif, tetapi cepat bosan, kurang bertanggung jawab, cenderung absensi, dan turnover-nya tinggi. Karyawan yang usianya lebih tua kondisi fisiknya kurang tetapi bekerja ulet, tanggung jawabnya besar, serta absensi dan turnover-nya rendah.

c) Pendidikan

Pendidikan merupakan suatu indikator yang mencerminkan kemampuan seseorang untuk dapat menyelesaikan suatu pekerjaan. Dengan latar belakang pendidikan pula seseorang dianggap akan mampu menduduki suatu jabatan tertentu.

d) Nilai Psikotest

Nilai psikotest merupakan serangkaian tes yang bertujuan untuk mengungkap sisi psikologis dari seseorang. Hasil inilah yang membantu perusahaan melihat sekilas bagaimana kepribadian dari calon karyawannya. 
e) Nilai Wawancara

Nilai wawancara diperoleh dari cara calon pelamar melakukan interaksi langsung dengan HRD, tes wawancara ini membantu memberikan penilaian berdasarkan nilainilai yang diinginkan oleh perusahaan.

\section{HASIL DAN PEMBAHASAN}

Perancangan Sistem Pendukung Keputusan Rekrutmen Karyawan

Perancangan sistem penunjang keputusan perekrutan karyawan dengan melakukan input data calon karyawan yang terdiri atas : nama, alamat, tempat tanggal lahir, pendidikan terakhir, pengalaman kerja, dan posisi yang diminati serta dilakukan penginputan data nilai psikotest dan wawancara. Adapun software yang digunakan dalam merancang sistem adalah Visual Studio 2019 dengan XAMPP dan mysql sebagai input database.

\section{Diagram Aliran Data}

Diagram alir sistem ini dapat dilihat pada Gambar 3.

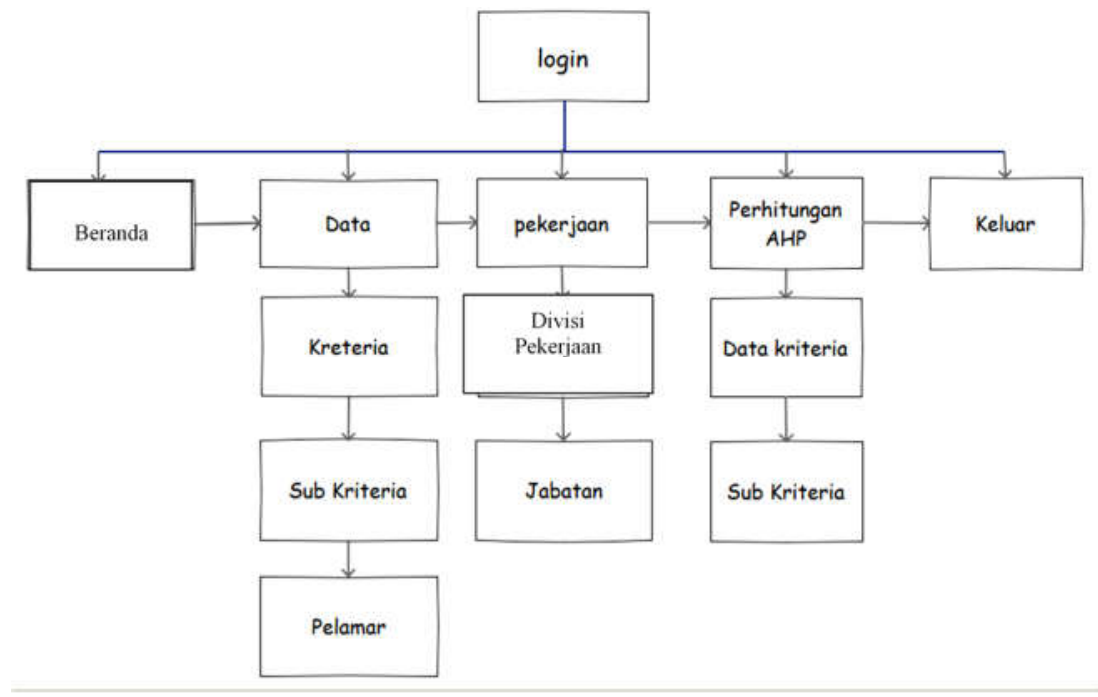

Gambar 3. Diagram Aliran Data Sistem

\section{Perancangan Diagram Konteks}

Diagram konteks menggambarkan hubungan entity luar, input dan output dari suatu sistem seperti pada Gambar 4.

Aliran proses 0 : Dari calon pelamar mengirim berkas lalu di proses oleh sistem, data pelamar yang telah di olah di terima HRD, setelah di verifikasi data pelamar kembali di olah di sistem setelah itu keluar laporan karyawan ke owner bersamaan dengan hasil perekrutan karyawan. 


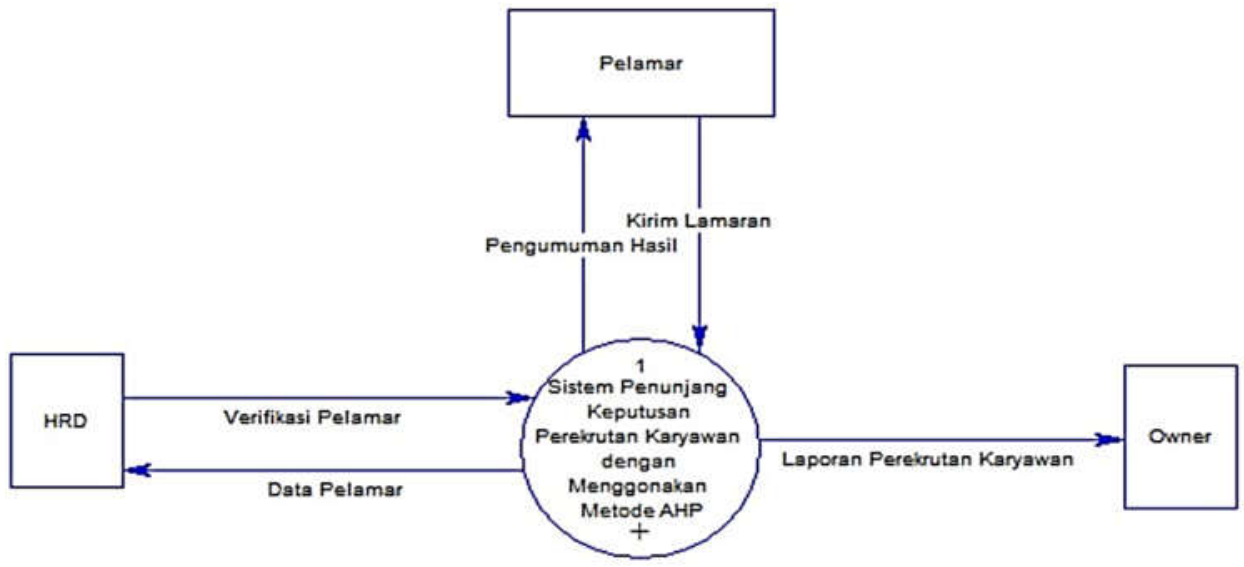

Gambar 4. Diagram Konteks Sistem

\section{Perancangan Data Flow Diagram (DFD)}

Aliran proses level 1 : Dari calon pelamar mengirim lamaran, berkas lamaran di periksa HRD, setelah itu data calon pelamar di input di sistem, setelah selesai di olah sistem, keluar pengumuman tes dan di kirim kembali ke calon karyawan, setelah itu calon karyawan mengikuti tes. Kemudian hasilnya di olah kembali di sistem. hasil perhitungan dari sistem di kembalikan ke HRD, pihak HRD membuat laporan, setelah laporan selesai diinformasikan ke pelamar lalu dibuat database beserta hasil di kirim ke owner. Daigram alirnya dapat dilihat seperti pada Gambar 5.

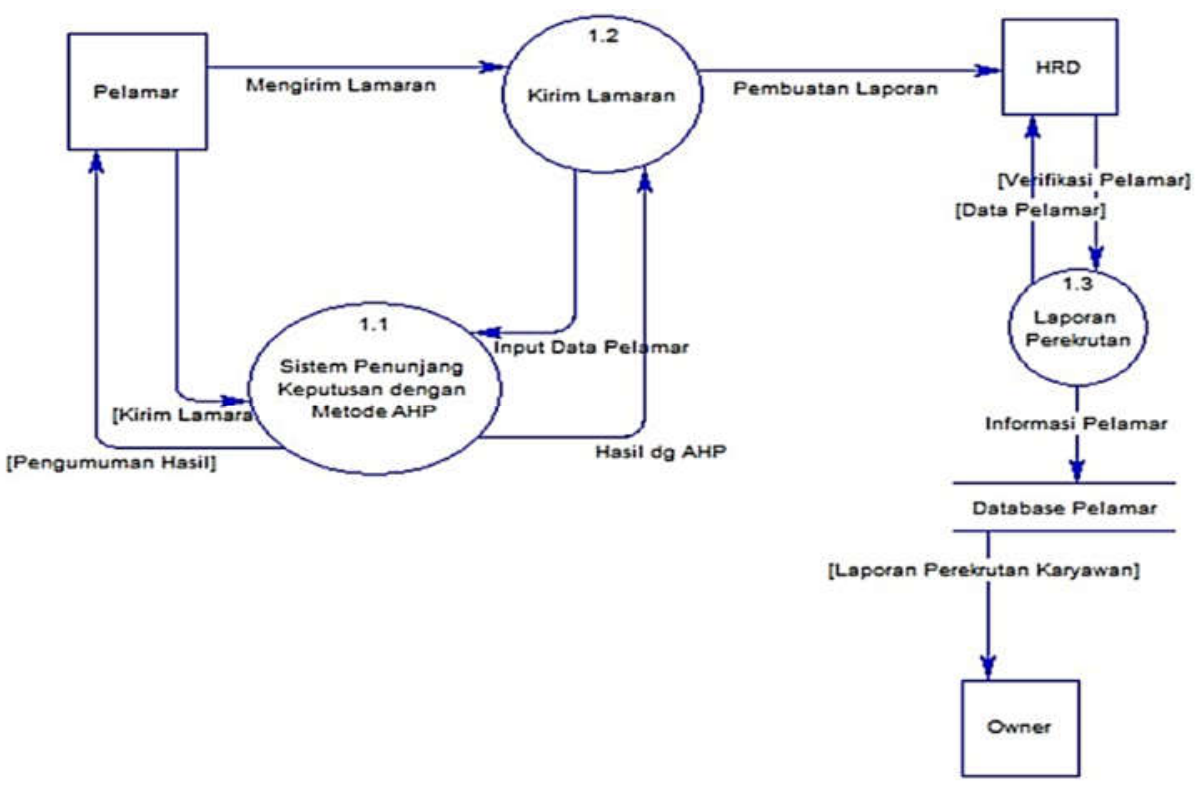

Gambar 5. DFD Rancangan Sistem

\section{Perancangan ERD (Entity Relationship Diagram)}

Dalam sistem penunjang keputusan perekrutan ini terdapat beberapa entitas, mulai dari ID calon karyawan, jabatan, divisi, kriteria keputusan (pengalaman kerja, usia, Pendidikan, nilai psikotest, dan nilai wawancara). Untuk menggambarkan hubungan atau relasi antar entitas, dibuat sebuah diagram ERD (Entity Relationship Diagram) seperti pada Gambar 6. 


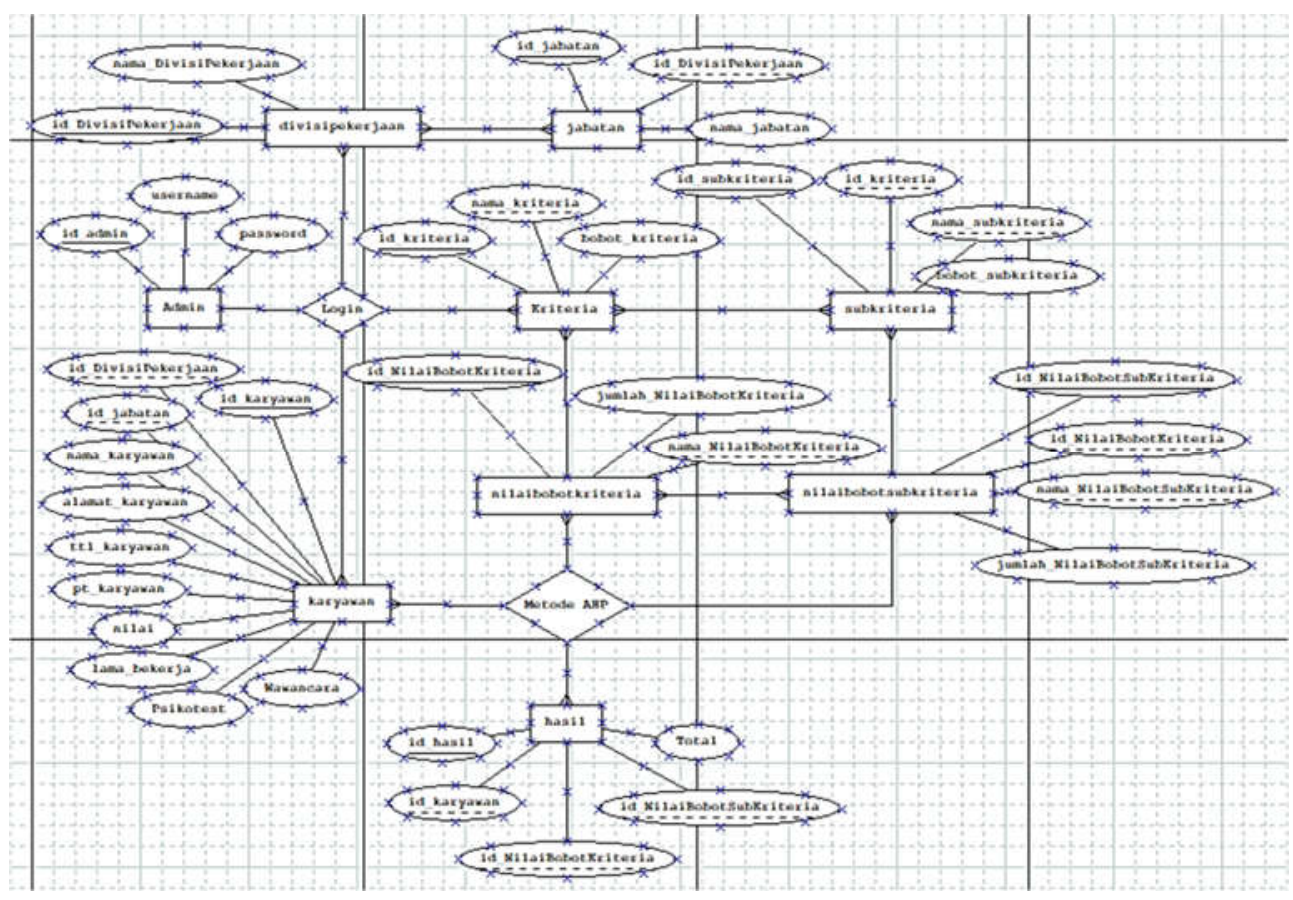

Gambar 6. Perancangan ERD Sistem

\section{Perancangan Konteks Sistem Informasi}

\section{Database karyawan}

Terdiri dari 8 (delapan) field, yaitu id_karyawan, id_DevisiPekerjaan, id_jabatan, nama_karyawan, alamat_karyawan, ttl_karyawan, pt_karyawan dan nilai seperti pada Gambar 7.

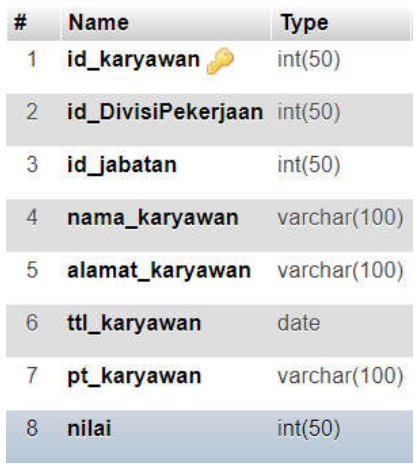

Gambar 7. Database karyawan

\section{Database Sub Kriteria}

Terdiri dari beberapa field, id_subkriteria, id_kriteria, nama_subkriteria, dan bobot_subkriteria seperti pada Gambar 8 .

\begin{tabular}{lll} 
\# & Name & Type \\
\hline 1 & id_subkriteria & int $(50)$ \\
\hline 2 & id_kriteria & int $(50)$ \\
\hline 3 & nama_subkriteria & varchar $(100)$ \\
\hline 4 & bobot_subkriteria & varchar(100) \\
\hline & Gambar 8. Database subkriteria
\end{tabular}




\section{Database Pekerjaan}

Terdiri dari beberapa field,id_pekerjaan, nama_pekerjaan, jabatan, dan jumlah_lowongan seperti pada Gambar 9.

\begin{tabular}{llll} 
\# & Name & Type & Collation \\
\hline 1 & id_pekerjaan & $\operatorname{int}(50)$ & \\
\hline 2 & nama_pekerjaan & $\operatorname{varchar}(100)$ \\
\hline 3 & jabatan & $\operatorname{varchar}(100)$ \\
\hline 4 & jumlah_lowongan & int(50)
\end{tabular}

Gambar 9. Database pekerjaan

\section{Database nilai bobot kriteria}

Terdiri dari beberapa field, yaitu id_nilaibobotkriteria, nama_nilaibobotkriteria, jumlah_nilai bobot kriteria seperti pada Gambar 10.

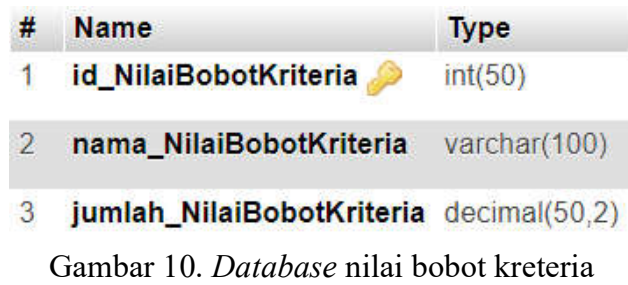

\section{Database hasil}

Terdiri dari beberapa filed yaitu, id_hasil, id_karyawan, id_nilaibobotkriteria, id_nilaibobotsubkriteria, dan total seperti pada Gambar $1 \overline{1}$.

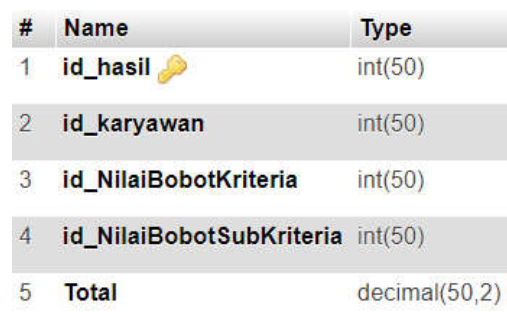

Gambar 11. Database hasil

\section{Perancangan Tatap Muka Sistem}

Berikut perencanaan tatap muka (interface) sistem informasi persediaan barang yang akan diusulkan pada PG Rajawali I seperti pada Gambar 12. 


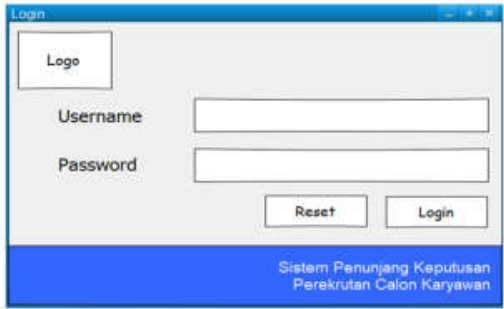

(a)

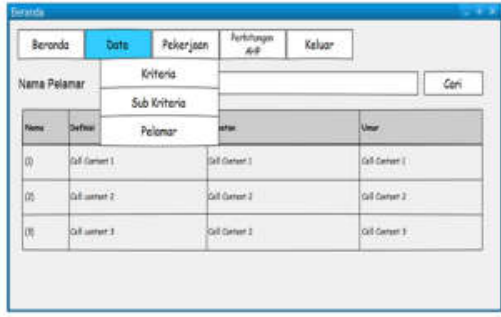

(c)

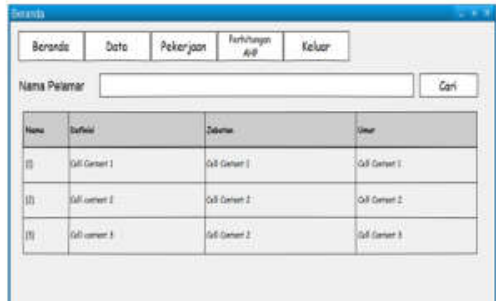

(b)

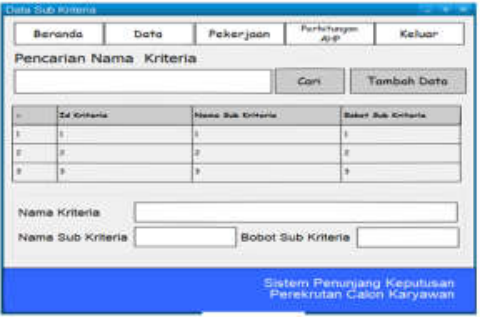

(d)

Gambar 12. Rancangan menu (a) Login; (b) Beranda; (c) Data; (d) Kriteria

\section{Menu Perhitungan AHP}

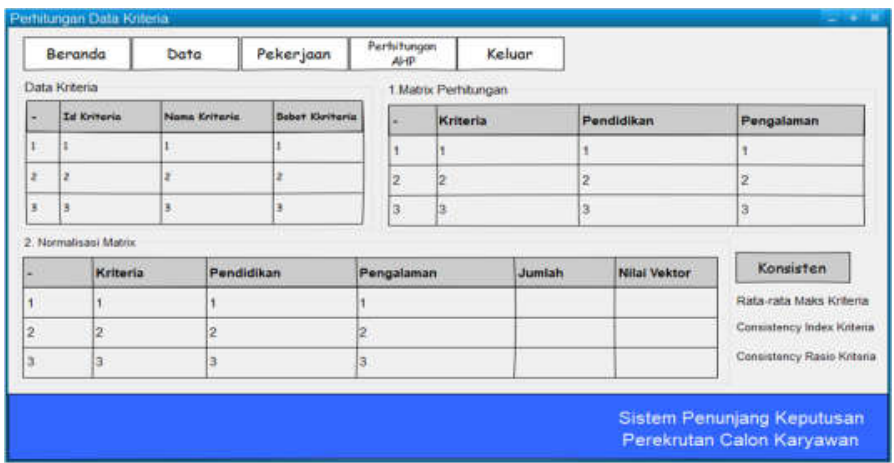

Gambar 13. Rancangan Menu Perhitungan Kriteria

\section{DAMPAK DAN MANFAAT}

Perancangan sistem terkomputerisasi yang dapat mendukung staff HRD di PT X dalam merekrut calon karyawan yang sesuai dengan spesifikasi perusahaan. Diharapkan adanya sistem ini dapat memangkas waktu perekrutan lebih cepat dan akurat sehingga terhindar dari kesalahan pendataan. Dengan demikian, sistem ini diharapkan dapat meningkatkan efisiensidan efektivitas sistem perekrutan karyawan. Perusahaan dapat menghemat waktu dan biaya terutama pada proses akhir yaitu penentuan calon karyawan berdasarkan bobot tertinggi.

\section{KESIMPULAN}

Hasil dari penelitian ini adalah sistem pendukung keputusan dengan visual studio 2019. Hasil perekrutan menjadi lebih cepat karena staff HRD tidak perlu mencari dokumen satu persatu. Selain itu, hasil menjadi lebih akurat karena dapat mengurangi tingkat kesalahan staff HRD pada proses awal pendataan dokumen sampai dengan proses 
pendataan hasil psikotes dan wawancara. Sistem ini juga dapat membantu pengambil keputusan dalam menentukan calon karyawan berdasarkan bobot tetinggi.

\section{UCAPAN TERIMA KASIH}

Ucapan terimakasih pada Universitas Widyagama Malang dan staff HRD PT. X, yang terlibat pada pembuatan sistem pendukung keputusan pada PT. X.

\section{REFERENSI}

Handoyo. (2013) 'Sistem Pendukung Keputusan Penerimaan Pegawai Dengan Metode AHP', SEMANTIK. Retrieved Oktober 20, 2019, from http://publikasi.dinus.ac.id/index.php/semantik/article/download/768/555

Mardianto, (2014) 'Optimizing Recruitment Strategy Recruitment Management', Jakarta: Pinasthika

Maulana, D. (2017) 'Perancangan Sistem Informasi Perekrutan Karyawan Pada Pt. Smap Indonesia Berbasis Web Programing', Jurnal Teknologi Pelita Bangsa, 7, 172-178.

Meiastoko, D. (2013) 'Implementasi Sistem Informasi Sumber Daya Manusia dalam Kegiatan Rekruitmen Karyawan (Studi pada PT Aneka Jasa Grhadika)' Jurnal Administrasi Bisnis (JAB), 6(3), 21-26 